\title{
APPLICATION OF DISTRIBUTED URBAN SENSOR NETWORKS FOR ACTIONABLE AIR QUALITY DATA
}

\author{
E. Morris ${ }^{1, *}$, X. Liu ${ }^{1}$, A. Manwar ${ }^{1}$, D. Y. Zang ${ }^{1}$, G. Evans ${ }^{2}$, J. Brook ${ }^{2}$, B. Rousseau ${ }^{2}$, C. Clark ${ }^{2}$, J. MacIsaac ${ }^{3}$ \\ ${ }^{1}$ A.U.G. Signals Ltd., Toronto, Canada - (eric.morris, xia, abhinav, yi)@augsignals.com \\ ${ }^{2}$ Southern Ontario Centre for Atmospheric Aerosol Research, Department of Chemical Engineering \& Applied Chemistry, \\ University of Toronto, Toronto, Canada - (greg.evans, jeff.brook, brice.rousseau)@utoronto.ca, carson.clark@mail.utoronto.ca \\ ${ }^{3}$ Office of the CAO, City of Oshawa, Canada-jmacisaac@oshawa.ca
}

Commission IV

KEY WORDS: Ambient Air Pollution, Air Quality Monitoring, Distributed Sensor Network, Smart Cities, Internet of Things

\begin{abstract}
:
Ambient air pollution continues to be a major human health burden around the world. Cities with existing smart data infrastructure, and those with smart city aspirations, would benefit from the integration of real-time data from an air quality sensor network. AirSENCE ${ }^{\mathrm{TM}}$ is one such sensor which monitors eight common pollutants at low cost. It has been deployed in Canada in cities of the Greater Toronto Area, e.g. the City of Oshawa, to augment the existing urban data network and study the impacts of traffic flow and land usage on air quality. Results reveal that distributed sensors are highly useful for detecting localized pollution events that would otherwise go undetected, providing policymakers with a valuable, actionable data for protecting public health. Coupling air quality sensors with other smart city data (traffic monitors in this case) was shown to provide a more comprehensive representation of how air pollutant levels are affected by human activity, which can better inform city planning decisions.
\end{abstract}

\section{BACKGROUND}

\subsection{Air Pollution Today}

Although great strides in air emissions mitigation technologies have been made in recent decades, air pollution remains a serious threat to public health around the world. Estimates of the number of premature deaths attributable to particulate matter less than $2.5 \mu \mathrm{m}$ in diameter $\left(\mathrm{PM}_{2.5}\right)$ in outdoor air worldwide vary between 4.2 million for 2016 (WHO, 2018) to 8.9 million for 2015 (Burnett et al., 2018). Out of these numbers, roughly nine-tenths are believed to have occurred in low- and middleincome countries (WHO, 2018). Other studies point out that $\mathrm{PM}_{2.5}$ does not fully account for the apparent mortality risk correlated with ambient pollution exposure, and that nitrogen dioxide $\left(\mathrm{NO}_{2}\right)$ and ozone $\left(\mathrm{O}_{3}\right)$ also contribute significantly (Crouse et al., 2015; Turner et al., 2016; Lelieveld et al., 2020). All three of these pollutants are well-known to contribute to cardiovascular and respiratory illnesses, as well as cancer. A growing body of research indicates that these may just be the most conspicuous health effects, and that air pollution can potentially impact many of the body's organs and affect everything from fertility rates to cognitive development to how well we sleep (Graff Zivin, Neidell, 2018; Schraufnagel et al., 2019). Perhaps even more distressing in light of recent world events, there is evidence that air pollution may not only increase our susceptibility to communicable pathogens (Cui et al., 2003) but can also potentially enhance the infectivity of virus particles (Groulx et al., 2018). The need for governments to measure air pollution accurately and proactively disseminate the results to the public is thus readily apparent.

\subsection{Motivation for More Sampling Sites}

Most cities in the developed world have at least one ambient air monitoring station which continuously samples and analyses air for locally relevant pollutants. While these stations use standardized sensors that are up to the task, their initial and operational costs and level of sophistication can restrict how widely they are deployed.

Studies of the sources, effects, and mitigation strategies of urban air pollution are only as good as the data they rely upon. Regulators attempting to introduce intervention strategies to control pollutant levels must be assured that the information they are provided is as reliable and accurate as possible, thus the sparseness of monitoring stations becomes problematic. While various dispersion models exist that can be used to predict pollutant levels at specific locations (Beelen et al., 2013; Siemens, 2013) their reliability is only as good as their input data. Real-world applications must rely on real-world measurement data (Berkowicz et al., 2006). In particular, a lack of roadside data introduces uncertainty for regulatory bodies attempting to introduce pollution mitigation strategies and makes it virtually impossible for them to evaluate the efficacy of regulations already in place (HEI, 2010).

\subsection{Application of Actionable Air Quality Data}

Sensor-network based assessment of air quality is growing rapidly but application of the resulting data is lagging. The literature contains much speculation and forecasting with regards to potential uses for this data, but discussion of tangible applications that have been implemented or are currently underway are lacking. Those that have been reported tend to consist of promoting public awareness for informed decision making. Clements et al. (2017) reported on a program in

\footnotetext{
* Corresponding author
} 
California's Imperial County in which a network of 40 low-cost air quality sensors are used to create a publicly accessible webplatform called IVAN (Identifying Violations Affecting Neighborhoods). The program provides real-time measurements of $\mathrm{PM}_{2.5}$ and particulate less than $10 \mu \mathrm{m}$ in diameter $\left(\mathrm{PM}_{10}\right)$ and makes recommendations regarding outdoor activity levels based on this data (IVAN, 2020).

A number of comparable citizen science projects have been initiated in Europe. Citi-Sense-MOB utilized low-cost sensors mounted on bicycles, automobiles, and public transit vehicles in Oslo, Norway to continuously transmit air quality data to servers (Castell et al., 2016; Schneider et al., 2016). This data was then combined with that obtained from models and monitoring stations to provide citizens with detailed air quality information via web and mobile applications. In Zurich, Switzerland, Mueller et al. (2016) similarly used data from lowcost PM sensors to produce models that generate minimal exposure routes for cyclists. This study was part of the OpenSense project, which is a community-based initiative to monitor urban air pollutants using wireless sensors. In several European countries, EveryAware was introduced as a means of engaging citizens to help collect real-time data for 8 pollutants (Loreto, 2014). The sensors were housed in a box which fits inside a small pack along with a battery for power; results were coupled to the user's Smartphone via Bluetooth, then sent automatically to a central server for public access.

Actionable air quality data refers to that which can be directly applied by industries, governments, and regulatory bodies to develop strategies, aid in decision making, and invoke reactive measures. One example is the use of distributed air quality sensor network data for intelligent traffic control. Siemens (2013) initiated the Sitraffic Scala/Concert system in Potsdam, Germany in 2013. Incorporating meteorological data and measurements of $\mathrm{NO}_{2}$ and $\mathrm{PM}_{10}$ into the city's traffic management system, traffic flow can be optimized in such a way as to reduce levels of $\mathrm{NO}_{2}$ and $\mathrm{PM}_{10}$. A similar European Space Agency development project called the Urban Traffic Management and Air Quality project (uTRAQ) has been demonstrated at three sites in England (Kettel et al., 2015). This project also incorporated earth observation to assess the impact of non-traffic sources and non-local "imported" air pollution. Both of these projects could stand to benefit greatly from the increased real-time data made available through a network of comprehensive air quality sensors distributed across their respective testing sites. The input of comprehensive real-world measurements would enhance the reliability of the traffic control strategies while helping to verify the efficacy of the air pollution models.

This study evaluated the performance of low-cost ambient air pollutant sensors by comparison with reference monitoring stations. The efficacy of distributed sensor networks for detection of local-scale air pollution events was evaluated, as was the interdependence of air pollution data with other Smart City data. The overall objective was to illustrate how distributed air quality monitoring can aid municipalities in obtaining actionable data for informed decision making.

\section{AIRSENCE'M: A CANADIAN APPROACH}

\subsection{Introduction to AirSENCE ${ }^{\mathrm{TM}}$}

AirSENCETM (Air SENsor for Chemicals in the Environment) is a compact and low-cost air monitoring product conceived of by the Southern Ontario Centre for Atmospheric Aerosols
Research (SOCAAR) at the University of Toronto and jointly developed with A.U.G. Signals Ltd. (AUG). It incorporates a multi-parameter sensor array with machine learning-based signal processing and data fusion to provide an industrial Internet of Things (IIoT) sensor network.

AirSENCETM actively draws air from the surrounding environment through a chamber in which an array of pollutant sensors is housed. The sensors take measurements continuously and average them every 2 minutes, at which point the results are transmitted to a host server for processing and online display. This system was designed for measurement of typical ambient air pollutants, i.e. $\mathrm{NO}_{2}, \mathrm{O}_{3}, \mathrm{PM}_{2.5}$, and $\mathrm{PM}_{10}$, as well as nitric oxide (NO), carbon monoxide (CO), sulphur dioxide $\left(\mathrm{SO}_{2}\right)$, and carbon dioxide $\left(\mathrm{CO}_{2}\right)$. Integrated metrics such as Air Quality Index (AQI) and Air Quality Health Index (AQHI) are also computed based on the user's geographic location.

Each AirSENCETM unit is pre-configured with the operational coefficients provided by the manufacturer for every individual air pollutant sensor. The devices are then rigorously tested in an outdoor environment alongside industry standard air monitoring equipment for a period of no less than two weeks. Final calibrations are done based on comparison of sensor output data with that of reference instruments. After field installation, machine learning algorithms on the server side facilitate hardware maintenance by actively correcting for sensor drift and issuing alerts for abrupt changes that are interpreted as possible sensor failures.

\subsection{GTA Satellite Smart City Project}

One of the GTA satellite cities - a municipality of more than 720 thousand inhabitants in the Greater Toronto Area (GTA) was chosen for this study because of its commitment to engaging the community, citizens and industry leaders to its Smart City endeavour, which uses data and communication technologies to create sustainable economic development, increase operational efficiency, improve the quality of government services and make improvements to community life. In 2018, the city initiated a pilot project with AUG and SOCAAR to deploy AirSENCETM units in strategic locations throughout the city as part of the City's recently installed smart city infrastructure to inform residents of air quality at the regional level with higher spatial resolution. Data gathered from across the city during this project is beneficial for assessing air quality impacts as well as reforming health, land use, transportation and other policies.

Six sites were selected to represent a variety of land uses and strategic monitoring areas (Figures 1 and 2). Among these are: a busy intersection near a cement plant, two school pick-up/dropoff zones, an intersection nearby to a major airport, a city-
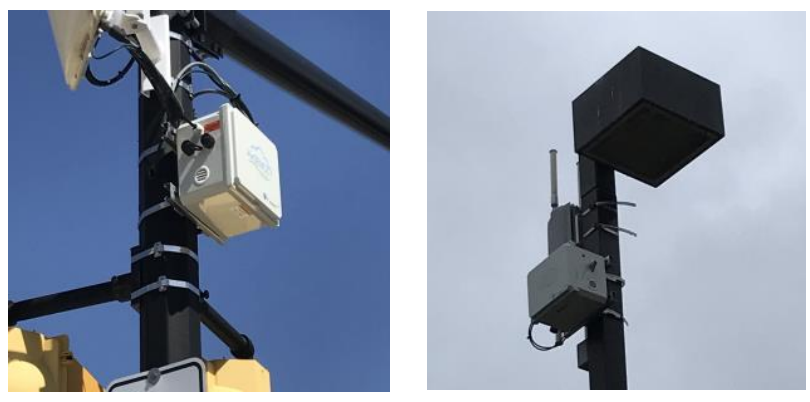

Figure 1. AirSENCETM units in the GTA Satellite Smart City. 


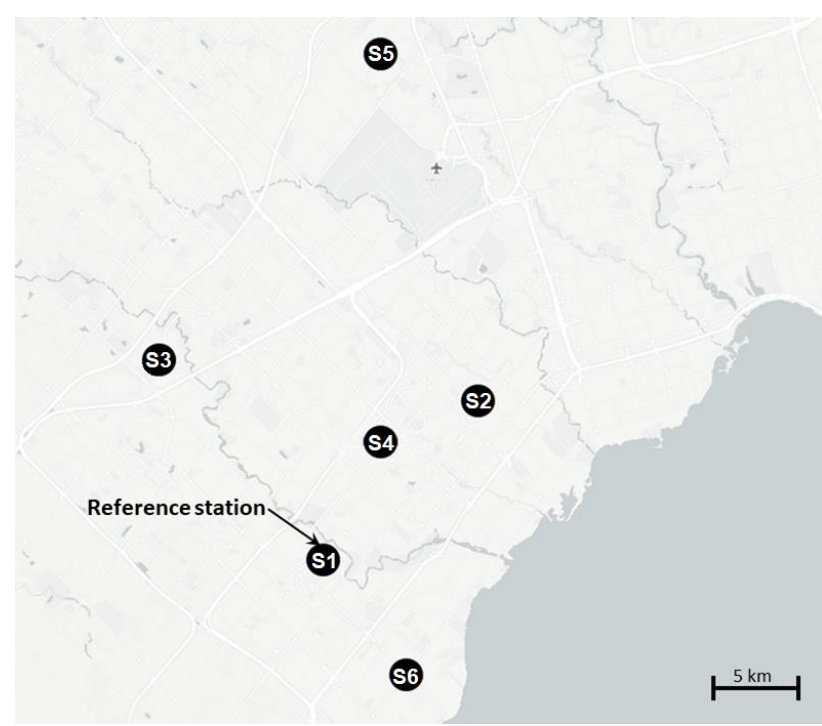

Figure 2. Locations of AirSENCETM devices S1-S6 in the GTA Satellite Smart City, Ontario.

operated public event space, and near a regional air monitoring station. At each site, the AirSENCETM unit was installed on an existing light or traffic signalling pole at a height of $3 \mathrm{~m}$. Raw sensor data was transmitted via Ethernet and wireless infrastructure previously installed by the Satellite City to provide capacity for Smart sensors.

\subsection{TeachingCity Oshawa Initiative}

TeachingCity Oshawa is a collaborative effort between the City of Oshawa and its education and research partners focused on addressing urban issues with real-world, sustainable solutions while fostering innovative educational projects. AUG and SOCAAR are working with the Oshawa to better understand the relationship between air quality and traffic movement in the city's downtown centre. Analysis of these data will help the City assess the impact of traffic priorities in the downtown core and how changes affect both air quality and traffic patterns. Findings will also help the City identify opportunities to improve the pedestrian experience in the downtown.

Four AirSENCETM units were installed around the perimeter of a city block in downtown Oshawa (Figures 3 and 4). Co-located with these devices were four North Line FOX radar systems to quantify passing vehicles and characterize them based on length. Each pair of AirSENCE ${ }^{\mathrm{TM}}$ and FOX units is located on a one-way street to facilitate the analysis of traffic flow and pollutant levels. The devices were installed at a height of $3 \mathrm{~m}$ on light or traffic signalling poles, and the sensor readings were transmitted to the server via $3 \mathrm{G}$ cellular network.
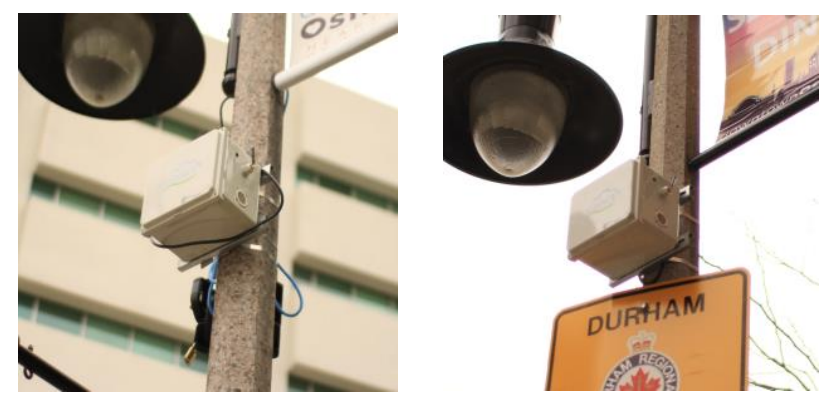

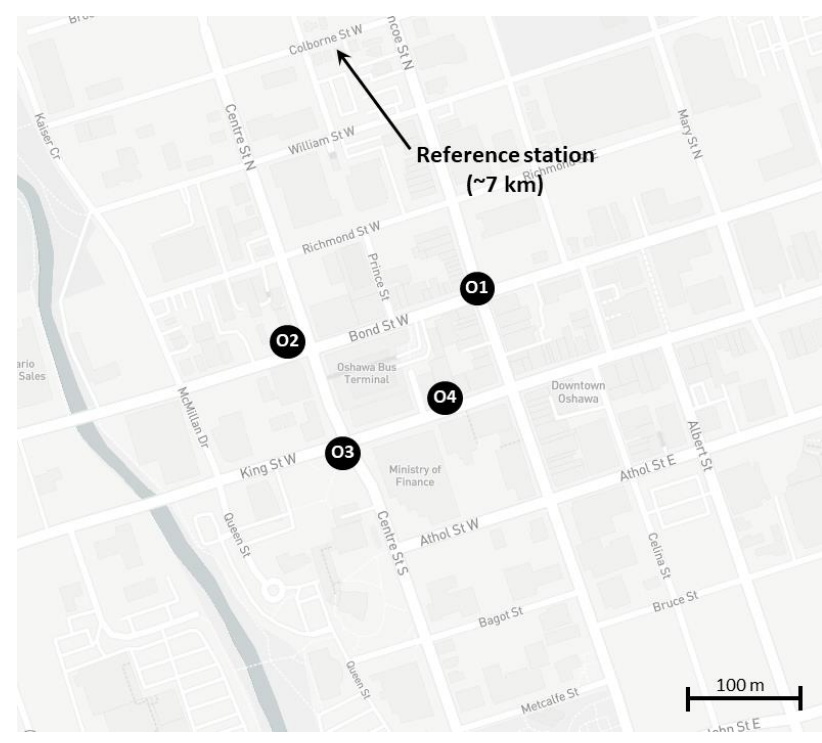

Figure 4. Locations of AirSENCETM devices O1-O4 in Oshawa, Ontario.

\section{ANALYSIS OF AIR QUALITY SENSOR READINGS}

\subsection{Observations from the GTA Satellite Smart City Sensors}

Figures 5 and 6 show hourly averaged diurnal patterns for $\mathrm{O}_{3}$ and $\mathrm{NO}_{2}$ concentrations from the six AirSENCE ${ }^{\mathrm{TM}}$ devices across the GTA Satellite City for weekdays during the month of August 2019. Hourly averaged reference measurements from the nearest ambient air monitoring station are overlaid. Weekend periods were not included in the averaging calculation as the intention was to capture the normal weekday cycles of $\mathrm{O}_{3}$ and $\mathrm{NO}_{2}$ due to rush hour traffic.

Figure 5 indicates that AirSENCE ${ }^{\mathrm{TM}}$ measurements across the city substantially capture the daily trends of $\mathrm{O}_{3}$ concentration as measured by the reference station. $\mathrm{O}_{3}$ is a secondary pollutant produced through reaction of other pollutants in the atmosphere in the presence of UV light, thus it is generally well-dispersed on a regional scale. This is demonstrated by the general agreement in $\mathrm{O}_{3}$ measurements observed, although differences across the AirSENCE ${ }^{\mathrm{TM}}$ and reference measurements can be seen, particularly at the daily peaks and valleys, and are quantified as relative mean absolute error (RMAE) as defined in Equation 1:

$$
R M A E=\frac{\frac{1}{n} \sum_{i=1}^{n}\left|X_{i}-R_{i}\right|}{R_{\text {mean }}}=\frac{M A E}{R_{\text {mean }}}
$$

Where $\quad X_{i}=$ measured pollutant concentration at time $i$ $R_{i}=$ reference pollutant concentration at time $i$ $R_{\text {mean }}=$ mean reference pollutant concentration $n=$ number of data points $M A E=$ mean absolute error,

These differences are in part be due to measurement errors stemming from the inherent difficulties of measuring $\mathrm{O}_{3}$ with low-cost sensors, and recent developments have effectively mitigated these.

Figure 3. AirSENCETM units in downtown Oshawa. 
Considerably greater divergence is seen for AirSENCETM $\mathrm{NO}_{2}$ measurements in different parts of the city (Figure 6). This is consistent with $\mathrm{NO}_{2}$ being more heterogeneous, generally peaking in cities near busy roadways and industrial sources, and diminishing rapidly with distance (Beckerman et al., 2008; Gordon et al., 2012; Baldwin et al., 2015). This is evident through the higher RMAE values of $\mathrm{NO}_{2}$ as compared with those of $\mathrm{O}_{3}$. Even Device $\mathrm{S} 1$, which is located a relatively short distance of $320 \mathrm{~m}$ from the reference station, shows a high difference with the reference $\mathrm{NO}_{2}$ data. Greater variability in $\mathrm{NO}_{2}$ concentration are expected across urban areas, which highlights the need for distributed air quality sensor networks where localised pollutant measurements are needed. Of note are the higher morning rush hour concentrations at sites S3 and S5 which are located on busy roads.

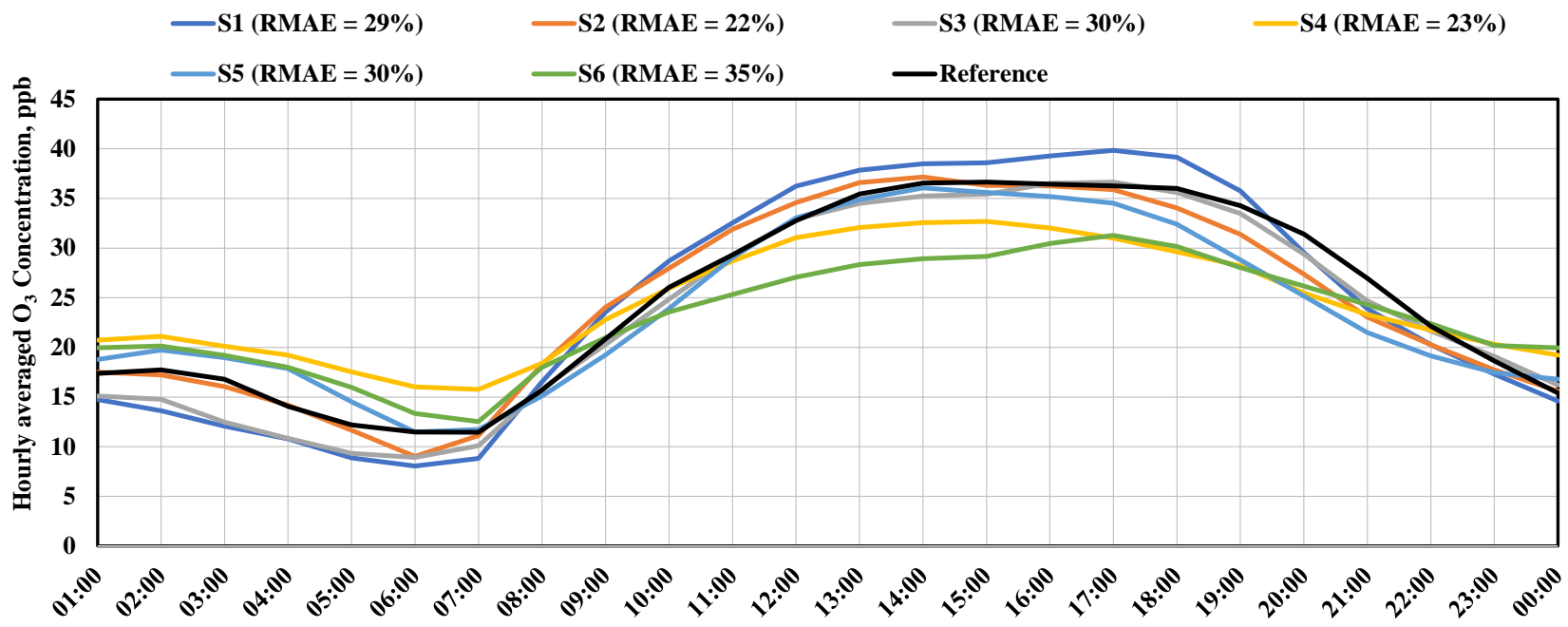

Figure 5. Hourly averaged $\mathrm{O}_{3}$ concentrations based on AirSENCE ${ }^{\mathrm{TM}}$ and reference measurements for weekdays in the month of August 2019 in the GTA Satellite Smart City, Ontario. Relative mean absolute errors are indicated for each AirSENCE ${ }^{\mathrm{TM}}$ device.

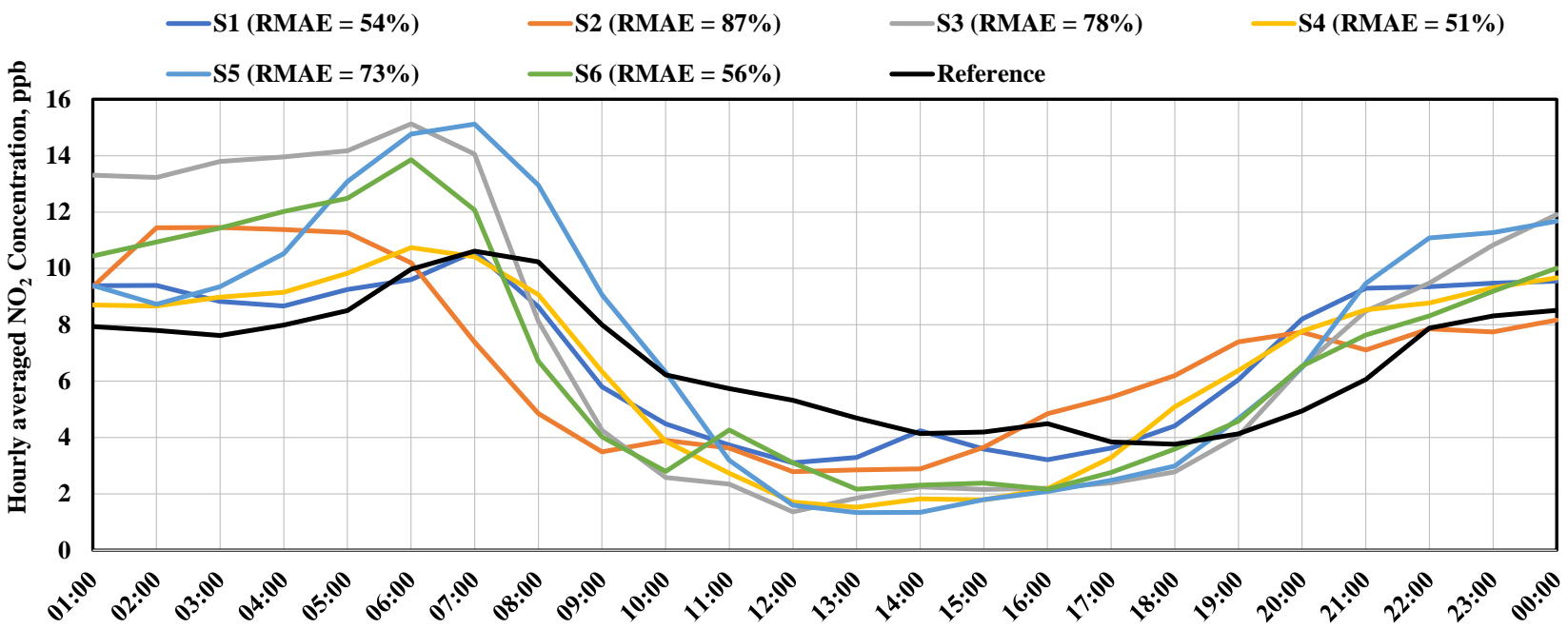

Figure 6. Hourly averaged $\mathrm{NO}_{2}$ concentrations based on AirSENCE ${ }^{\mathrm{TM}}$ and reference measurements for weekdays in the month of August 2019 in the GTA Satellite Smart City, Ontario. Relative mean absolute errors are indicated for each AirSENCE ${ }^{\mathrm{TM}}$ device.

Even for pollutants which tend to vary on a regional level, local hotspots can occur at or near point sources of emissions. These events, which may or may not be short-lived, often go undetected by ambient air quality monitoring stations. Examples of this are illustrated by Figures 7 and 8, which show levels of $\mathrm{PM}_{2.5}$ and $\mathrm{CO}$ for the six AirSENCETM installations in the GTA Satellite Smart City. Device S4 is located nearby to the city's open-air public venue used for many festivals and events. In the month of July 2019, this device detected notable spikes in local air pollutant levels that were otherwise unobserved. The timing of these pollution events coincided with events known to have occurred at this location. In these cases, the sources of pollutants can be traced to fireworks (as in the Canada day celebrations on July 1), food trucks and diesel generators (a cultural festival on July 6-7), and the use of small combustion engines (a timbersports competition on July 25-27). In other locations primary factors may include construction projects, heavy truck traffic, and industrial activities.

Municipalities often have limited control over the usage of public infrastructure like major roadways and privately owned parking lots; decisions on how these are used tend to be the 
jurisdiction of different authorities. The public events square, on the other hand, is an example of where the City has the ability to take actions based on data obtained by Smart City technologies. Data clearly indicating the presence of locally significant pollutant plumes originating from particular events can readily be used by policymakers to implement regulations in the interest of public safety. Examples might include stipulations regarding the placement of diesel generators or heightened enforcement of idling bylaws.

\subsection{Observations from Oshawa Sensors}

In Figure 9, levels of $\mathrm{PM}_{2.5}$ are compared with reference data measured at the nearest ambient air quality monitoring station, located approximately $7 \mathrm{~km}$ north of the AirSENCE ${ }^{\mathrm{TM}}$ sensors.

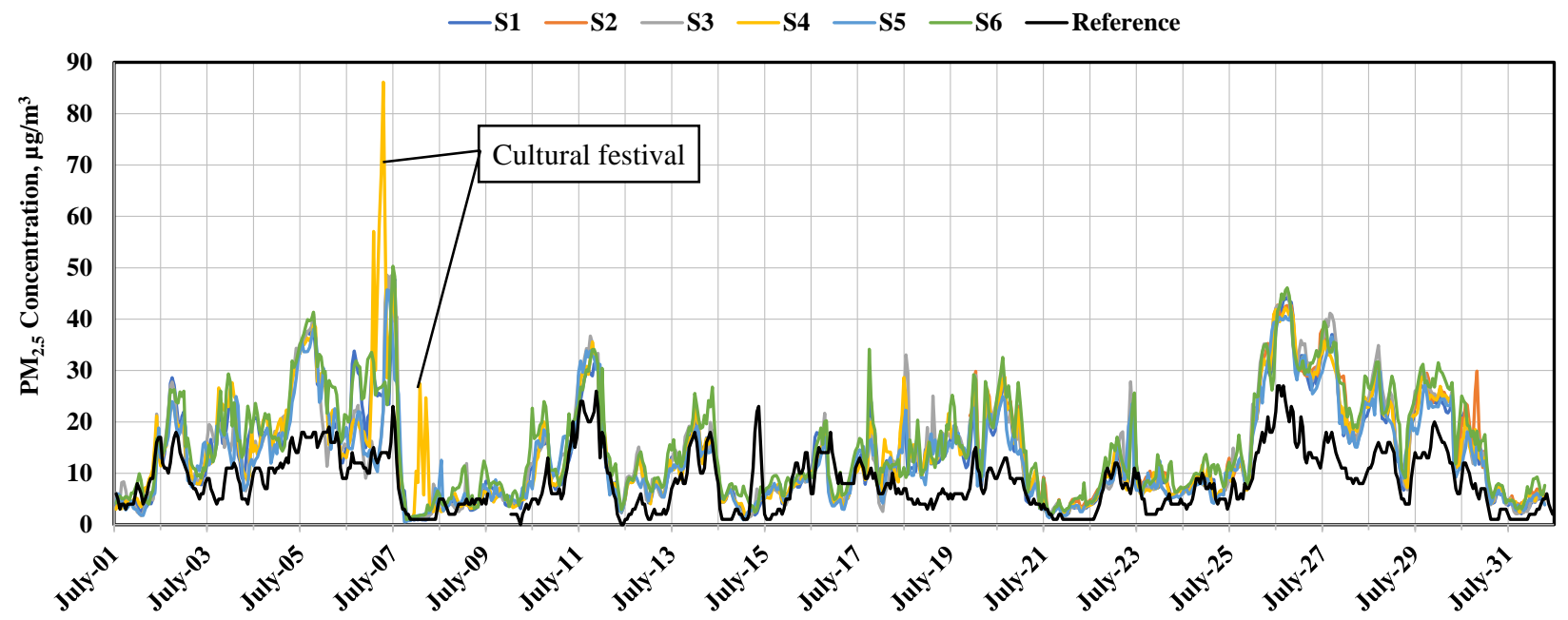

Figure 7. $\mathrm{PM}_{2.5}$ concentrations based on AirSENCE ${ }^{\mathrm{TM}}$ and reference measurements for the month of July 2019 in the GTA Satellite Smart City, Ontario.

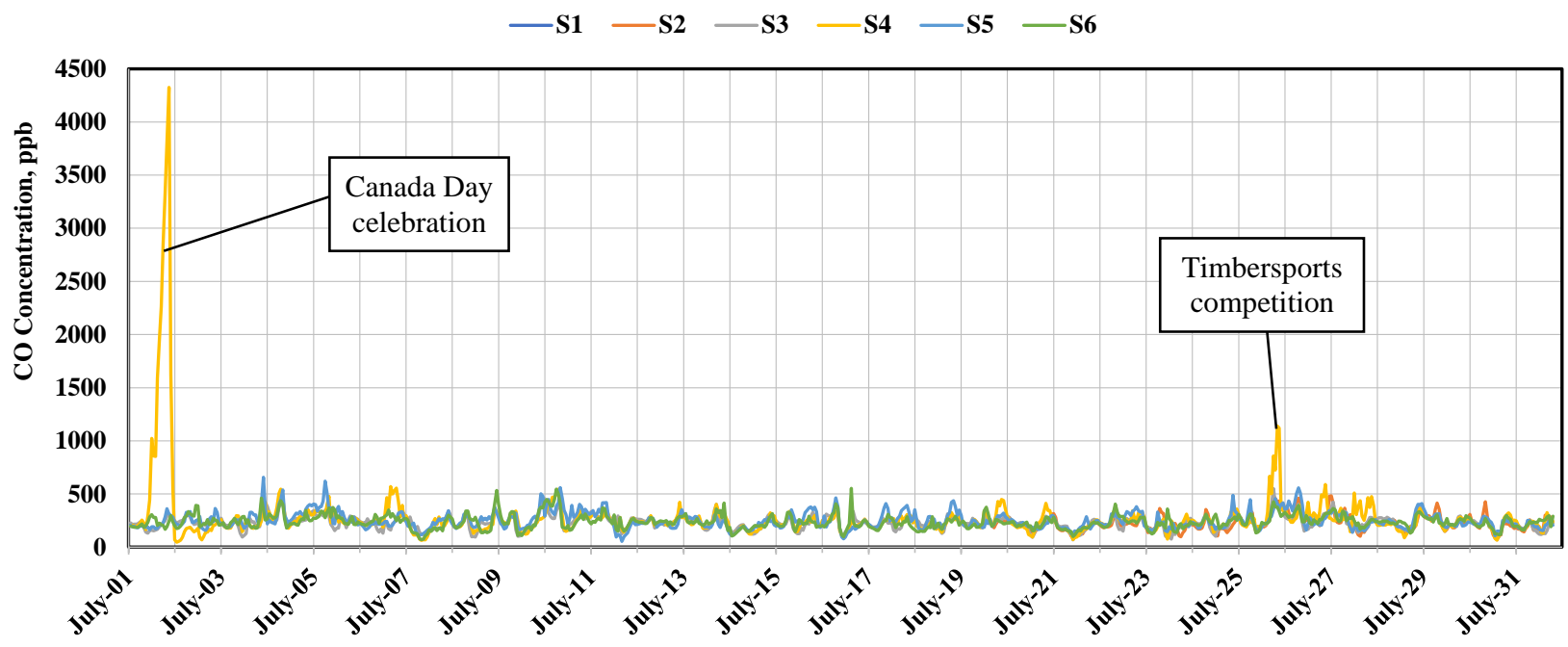

Figure 8. CO concentrations based on AirSENCE ${ }^{\mathrm{TM}}$ measurements for the month of July 2019 in the GTA Satellite Smart City, Ontario. (CO measurements unavailable from the reference station)

The four AirSENCETM units located in downtown Oshawa agree extremely well with one another and-in general-with the reference instrument at the ambient air quality monitoring station. It can be seen that all four AirSENCETM readings occasionally display peaks which were not observed by the reference. Unlike the instances shown in Figures 7 and 8, these peaks do not correspond with any known man-made sources or events in Oshawa that could explain their presence. These peaks do, however, tend to coincide with stormy and/or foggy conditions, which illustrates a known shortcoming of the optical sensors used: they tend to overshoot under high-humidity conditions. Similar instances of high $\mathrm{PM}_{2.5}$ readings that were consistent among AirSENCETM units but not observed by the reference station can be seen in Figure 7 for the GTA Satellite Smart City during the month of July. AUG and SOCAAR are currently working to implement humidity compensation to improve the $\mathrm{PM}_{2.5}$ readings using humidity measurements of AirSENCETM.

Traffic data obtained using North Line's FOX systems were compared at three locations with average hourly levels of $\mathrm{CO}_{2}$ monitored by the AirSENCETM units for weekdays during the 
period of August 12 to September 25, 2019 (Figure 10). At each location, $\mathrm{CO}_{2}$ levels spiked between 8 and 9 AM on weekdays, consistent with the morning rush hour. Traffic levels were not observed to diminish throughout the day in the downtown core of Oshawa, thus it might be expected that pollutants associated with vehicle exhaust would remain at elevated concentrations. This was not the case, though, as $\mathrm{CO}_{2}$ was found to decrease to concentrations even lower than those measured overnight.
Pollutant concentrations also depend greatly upon local meteorology. Figure 10 compares the same weekday $\mathrm{CO}_{2}$ trends with averaged hourly windspeed over the same time period. It can readily be seen that, on average, windspeeds increased to nearly double their overnight levels in the early afternoon then diminished by late evening, inversely to $\mathrm{CO}_{2}$ concentration. It is thus apparent that higher average windspeeds during daytime hours prevent emitted pollutants - which, for the case of vehicular exhaust, include $\mathrm{CO}, \mathrm{NO}$, and $\mathrm{NO}_{2}$ in addition to $\mathrm{CO}_{2}$ - from concentrating near the point of emission.

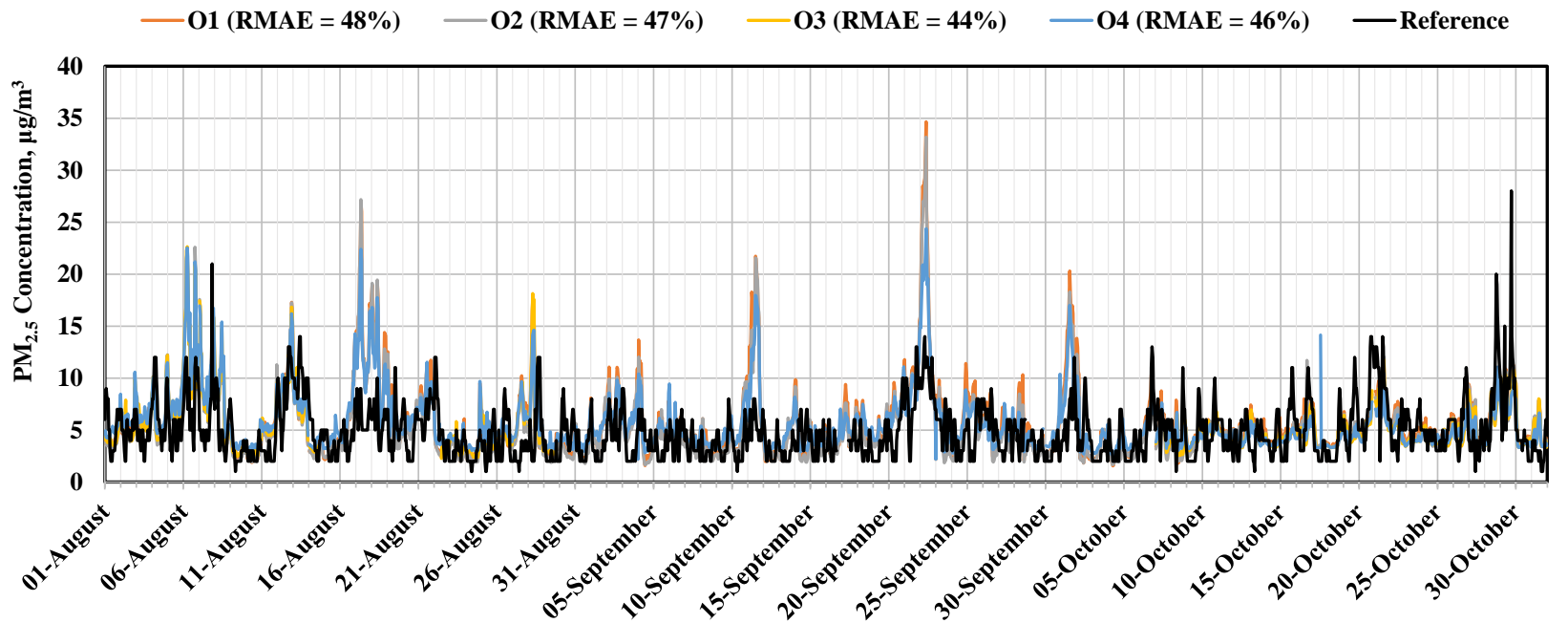

Figure 9. $\mathrm{PM}_{2.5}$ measurements based on AirSENCETM and reference measurements for the period between August 1 and October 31 , 2019 in Oshawa, Ontario
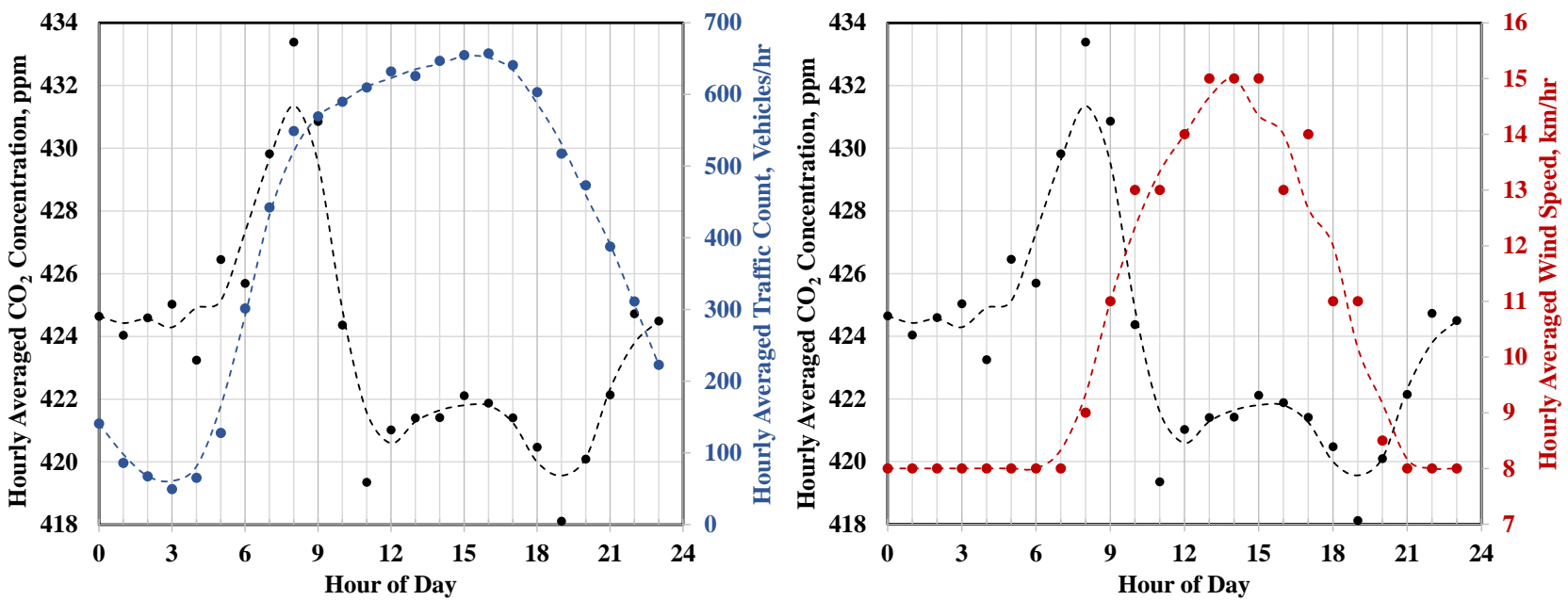

Figure 10. Comparison of average hourly $\mathrm{CO}_{2}$ levels with total observed hourly traffic density (left) and averaged hourly windspeed (right) for weekday periods for device O1 during the period of August 12-September 25, 2019. Highly similar results were found at each of the four monitoring sites.

These findings demonstrate that predicting when and where air pollution events occur is not necessarily a simple matter of identifying potential sources, e.g. rush hour traffic, festivals, etc. Based on traffic counting data alone, a city such as Oshawa may determine that the best course of action to reduce pollution exposure in the downtown area is to restrict vehicular access throughout the day-this would be burdensome for both commuters and local businesses. Combining real-time air monitoring sensors along with traffic counters would empower decision makers to assess the optimal times of day to enforce traffic controls without subjecting the public to excessively strict guidelines.

\section{CONCLUSIONS}

Distributed air quality sensor networks were installed in two cities within the Greater Toronto Area in Ontario. For the case of the GTA Satellite Smart City project, good agreement was generally found between the six installed devices and the City's ambient air monitoring station for regional scale pollutants, 
effectively demonstrating the validity of the sensor measurements. From the standpoint of actionable air quality data, however, the more beneficial measurements are those of local-scale pollutants (e.g. $\mathrm{NOx}$ ) and pollution events that cannot be reliably monitored with sparsely distributed monitoring stations. Given the known impacts of air pollution on human health, detection of such events should be an important component of a smart city's data usage strategy.

The example of Oshawa showed that air monitoring data can readily supplement that of other widely used smart city sensors such as traffic counters. Conventional data provides very useful information, but this is just a piece of a larger puzzle; with localized air quality data, city planners and regulatory agencies can make better-informed decisions for projects that involve public health considerations such as traffic mitigation, heavy construction, and urban renewal efforts.

The studies discussed here demonstrate the effectiveness of AirSENCETM as a tool for providing cities with actionable air quality data, however there are areas for improvement. Current research efforts are effectively mitigating the measurement issues described above, such as disagreement with reference measurements for regional-scale pollutants and positive interferences in PM readings due to high humidity levels. These improvements are being implemented and fine-tuned as of the writing of this paper and will be incorporated into all future iterations of AirSENCETM.

There exists great potential for enhanced geospatial visualization of air pollutant locations and patterns based on AirSENCE ${ }^{\mathrm{TM}}$ data. Forthcoming research will incorporate this data into time-average land use regression models to enable interpolation of concentrations surfaces based on parameters such as traffic density, population, green space, and industrial activity. This modelling will not capture day-to-day temporal variability such as the episodes noted in Figures 7 and 8 Predictions of ambient pollutant levels will also become possible using machine learning techniques as more historical data is accumulated by the AirSENCETM units. The adoption of open source data platforms, such as OGC SensorThings API, will be investigated to facilitate easier interoperability with complementary Smart City data.

\section{REFERENCES}

Baldwin, N. et al., 2015. Factors affecting pollutant concentrations in the near-road environment. Atmos. Environ., Vol. 115, 223-235. doi.org/10.1016/j.atmosenv.2015.05.024.

Beckerman, B. et al., 2008. Correlation of nitrogen dioxide with other traffic pollutants near a major expressway. Atmos. Environ., Vol. $\quad$ 42(2), $275-290$. doi.org/10.1016/j.atmosenv.2007.09.042.

Beelen, R. et al., 2013. Development of $\mathrm{NO}_{2}$ and $\mathrm{NO}_{\mathrm{x}}$ land use regression models for estimating air pollution exposure in 36 study areas in Europe - The ESCAPE project. Atmos. Environ., Vol. 72, 10-23. doi.org/10.1016/j.atmosenv.2013.02.037.

Berkowicz, R.; Winther, M.; Ketzel, M., 2006. Traffic pollution modelling and emission data. Environ. Modell. Software, Vol. 21(4), 454-460. doi.org/10.1016/j.envsoft.2004.06.013.

Burnett, R. et al., 2018. Global estimates of mortality associated with longterm exposure to outdoor fine particulate matter. Proc.
Nat. Acad. Sci. USA, Vol. 115(58), 9592-9597. doi.org/10.1073/pnas.1803222115.

Castell et al., 2016. Supporting Sustainable Mobility Using Mobile Technologies and Personalized Environmental Information: The Citi-Sense-MOB Approach in Oslo, Norway. In Marx Gómez, J. et al. (eds.), Advances and New Trends in Environmental and Energy Informatics, 199-218. Springer International Publishing, Switzerland 2016. doi.org/10.1007/978-3-319-23455-7.

Clements, A.L.; Griswold, W.G.; Abhijit R.S.; Johnston, J.E.; Herting, M.M.; Thorson, J.; Collier-Oxandale, A.; Hannigan, M., 2017. Low-Cost Air Quality Monitoring Tools: From Research to Practice (A Workshop Summary). Sensors, Vol. 17(11), 2478-2498. doi.org/10.3390/s17112478.

Crouse, D.L. et al., 2015. Ambient $\mathrm{PM}_{2.5}, \mathrm{O}_{3}$, and $\mathrm{NO}_{2}$ Exposures and Associations with Mortality over 16 Years of Follow-Up in the Canadian Census Health and Environment Cohort (CanCHEC). Environ. Health Perspect., Vol. 123(11), 1180-1186. doi.org/10.1289/ehp.1409276.

Cui, Y. et al., 2003. Air pollution and case fatality of SARS in the People's Republic of China: an ecologic study. Environ. Health, Vol. 2(15). doi.org/10.1186/1476-069X-2-15.

Gordon, M. et al., 2012. Measured and modeled variation in pollutant concentration near roadways. Atmos. Environ., Vol. 57, 138-145. doi.org/10.1016/j.atmosenv.2012.04.022.

Graff Zivin, J., Neidell, M., 2018. Air pollution's hidden impacts. Science, Vol. 359(6371), 39-40. doi.org/ 10.1126/science.aap7711.

Groulx, N. et al., 2018. The Pollution Particulate Concentrator (PoPCon): A platform to investigate the effects of particulate air pollutants on viral infectivity. Sci. Total Environ. Vol. 628-629, 1101-1107. doi.org/10.1016/j.scitotenv.2018.02.118.

HEI Panel on the Health Effects of Traffic-Related Air Pollution. 2010. Traffic-Related Air Pollution: A Critical Review of the Literature on Emissions, Exposure, and Health Effects, pp. 2-36. HEI Special Report 17. Health Effects Institute, Boston, MA.

IVAN, 2020. Ivan Air Monitoring. Online: https://ivanimperial.org/air. Cited on April 1, 2020.

Kettel, C. et al., 2015. Urban traffic management and air quality project. Intelligent Transport Systems (UK) Review, November 2015 issue.

Lelieveld, J. et al., 2020. Loss of life expectancy from air pollution compared to other risk factors: a worldwide perspective. Cardiovasc. Res., March 3, 2020. doi.org/10.1093/cvr/cvaa025.

Loreto, V., 2014. EveryAware: Enhance Environmental Awareness through Social Information Technologies. Project Final Report of EU FP7 ICT Project No. 265432. Online: http://www.everyaware.eu/resources/deliverables/D7.3.pdf. Cited on April 1, 2020.

Mueller, M.D. et al., 2016. Statistical modelling of particle number concentration in Zurich at high spatio-temporal resolution utilizing data from a mobile sensor network. Atmos. 
Environ., $\quad$ Vol. $\quad 126, \quad 171-181$. doi.org/10.1016/j.atmosenv.2015.11.033

Schneider, P. et al., 2017. Mapping urban air quality in near real-time using observations from low-cost sensors and model information. Environ. Int., Vol. 106, 236-247. doi.org/10.1016/j.envint.2017.05.005

Schraufnagel et al., 2019. Air Pollution and Noncommunicable Diseases - A Review by the Forum of International Respiratory Societies' Environmental Committee, Part 1: The Damaging Effects of Air Pollution. Chest, 155(2), 409-416. doi.org/ 10.1016/j.chest.2018.10.042.

Siemens AG, 2018. Sitraffic Traffic Center Systems. URL: https://assets.new.siemens.com/siemens/assets/api/uuid:5b21b1 7c86faa4bb6c3b2766d2f4c303f46abdf3/version:1520603474/sit raffic-centrals-v2-en-180120.pdf. Cited on March 20, 2020.

Turner, M.C. et al., 2016. Long-Term Ozone Exposure and Mortality in a Large Prospective Study. Am. J. Respir. Crit. Care Med., Vol. 193(10), 1134-1132. doi.org/10.1164/rccm.201508-1633OC.

WHO, 2018. Ambient (outdoor) air pollution. URL: https://www.who.int/news-room/fact-sheets/detail/ambient(outdoor)-air-quality-and-health. Cited on March 30, 2020. 